\title{
The Evaluation of the thermal storage electric heating system Operation Management
}

\author{
Lu Jing ${ }^{1, *}$, Liu Lei ${ }^{2}$, Kong Weizheng ${ }^{1}$, and Pan Fangyuan ${ }^{2}$ \\ ${ }^{1}$ State Grid Energy Research Institute Co. LTD, Beijing, China \\ ${ }^{2}$ State Grid (Beijing) Integrated Energy Planning and D\&R Energy Institute Co. LTD, Beijing, China
}

\begin{abstract}
Replacing fossil energy with the high proportion of renewable energy power in the field of enduse energy is the main way to reduce carbon emissions from energy combustion. Building heating is an important component in the field of end-use energy. The thermal storage electric heating system could use wind power during low power load periods at night for building heating. On the one hand, it helps to solve the problem of wind power accommodation, on the other hand it helps to achieve carbon emission reduction in the field of building heating. Based on the background of the thermal storage electric heating system for wind power accommodation, the influencing factors that affect the efficiency and benefits of electric heating system is analysed, and fuzzy comprehensive evaluation method based on analytic hierarchy process (AHP) is used to construct regenerative electric heating system operation management evaluation system.
\end{abstract}

\section{Introduction}

More than 120 countries covering 51 percent of global GHG emissions have net-zero goals that are formally adopted, announced or under consideration ${ }^{[1]}$. If the United States of America adopts a net-zero GHG target by 2050 , as suggested in the Biden-Harris climate plan, the share would increase to 63 percent. The use of fossil energy is one of the main sources of carbon dioxide emissions from human activities. In the future, replacing fossil energy with the high proportion of renewable energy power and improving energy utilization efficiency in the field of end-use energy is the main way to reduce carbon emissions from energy combustion and achieve the goal of carbon neutrality. Building heating is an important component in the field of end-use energy. Eelectric heating with heat storage system could use wind power during low power load periods at night for building heating. On the one hand, it helps to solve the problem of wind power accommodation, on the other hand it helps to achieve carbon emission reduction in the field of building heating ${ }^{[2,3]}$.

High investment costs and difficulties in coordination of the interests of all stakeholders are the main bottlenecks encountered in the promotion and application of the thermal storage electric heating system. The immature operation management evaluation mechanism affects the economic benefits and use efficiency of the thermal storage electric heating system. Based on the background of the thermal storage electric heating system for wind power accommodation, this paper analyzes the influencing factors that affect the efficiency and benefits of electric heating system, and constructs an operation management evaluation method that considers the efficiency and benefits of the thermal storage electric heating system.

\section{Fuzzy comprehensive evaluation based on analytic hierarchy process}

The analytic hierarchy process is an important method for decision-making management evaluation ${ }^{[4]}$, but it has some drawbacks which could not solve the problems of ambiguity and uncertainty in the process of management evaluation. The fuzzy comprehensive evaluation based on the analytic hierarchy process, using the principle of fuzzy linear transformation and the principle of maximum membership to comprehensively , considering various factors related to the evaluated system, fully reflect the problems of ambiguity and uncertainty in the evaluation. The indicators at the index level are comprehensively evaluated at first, and then pass them upwards to the target level. Finally comprehensive evaluation results are obtained ${ }^{[5]}$.

The main steps of the fuzzy comprehensive evaluation algorithm based on the analytic hierarchy process include five parts, as shown in as shown in Fig. 1.

\footnotetext{
*Corresponding author: lujing_xjtu@163.com
} 


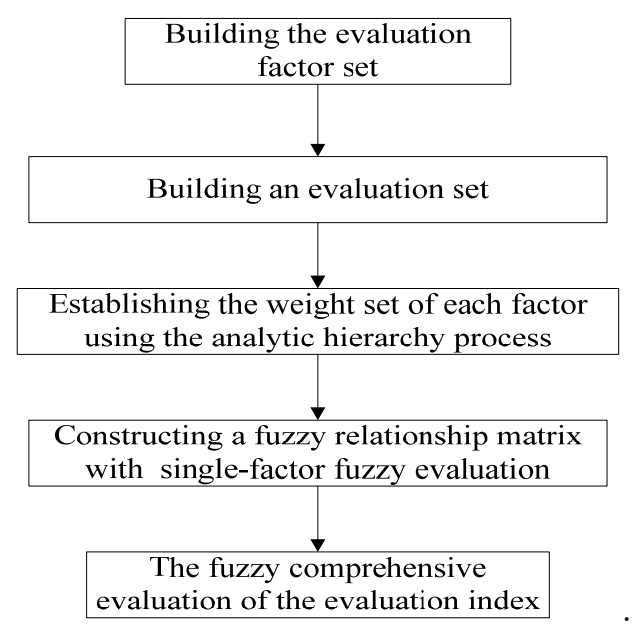

Fig.1The main steps of the fuzzy comprehensive evaluation

The template is used to format your paper and style the text. All margins, column widths, line spaces, and text fonts are prescribed; please do not alter them. You may note peculiarities. For example, the head margin in this template measures proportionately more than is customary. This measurement and others are deliberate, using specifications that anticipate your paper as one part of the entire proceedings, and not as an independent document. Please do not revise any of the current designations.

The first step is to determine the evaluation factor set.The influencing factors of the management evaluation object constitute a set, called a factor set, which can be expressed as:

$$
U=\left\{U_{1}, U_{2}, U_{3}, \ldots, U_{m}\right\}
$$

The second step is to classify according to the evaluation objectives and establish an evaluation set. The evaluation set is a group of evaluation results given by experts. Experts score the evaluation objects according to industry standards and their own experience, which can be expressed as:

$$
U=\left\{U_{1}, U_{2}, U_{3}, \ldots, U_{m}\right\}
$$

$V_{i}(i=1,2,3, \ldots, n)$ is Evaluation index, $n$ is the evaluation level.

The third step is to use the analytic hierarchy process to establish the weight set of each factor. The analytic hierarchy process is used to obtain the weight value of each evaluation index, which indicates the degree of importance of each index to the evaluation target. The weight set composed of all factor weights is a fuzzy subset of the factor set, which can be expressed as:

$$
\begin{aligned}
& W=\left\{w_{1}, w_{2}, w_{3}, \ldots, w_{m}\right\} \\
& \sum_{i=1}^{m} w_{i}=1
\end{aligned}
$$

The fourth step is constructing a fuzzy relationship matrix with single-factor fuzzy evaluation.A single evaluation factor is evaluated, and the degree of membership between the evaluation object and the evaluation set factor is determined. For quantitative indicators, it needs to be determined by membership function, and for qualitative indicators, it needs to be determined by expert scoring method to establish a fuzzy relationship matrix $U$ to $V$ obtained by a single-factor fuzzy evaluation $R$.

$$
R=\left[\begin{array}{cccc}
r_{11} & r_{12} & \cdots & r_{1 n} \\
r_{21} & r_{22} & \cdots & r_{2 n} \\
\vdots & \vdots & \ddots & \vdots \\
r_{m 1} & r_{m 2} & \cdots & r_{m n}
\end{array}\right]
$$

The fifth step is the fuzzy comprehensive evaluation of the evaluation index.The fuzzy comprehensive evaluation model can be composed of factor set, evaluation set and single factor evaluation set, which can be expressed as:

$$
B=W \circ R=\left(w_{1}, w_{2}, \ldots, w_{m}\right) \circ\left[\begin{array}{cccc}
r_{11} & r_{12} & \cdots & r_{1 n} \\
r_{21} & r_{22} & \cdots & r_{2 n} \\
\vdots & \vdots & \ddots & \vdots \\
r_{m 1} & r_{m 2} & \cdots & r_{m n}
\end{array}\right]
$$$$
=\left(b_{1}, b_{2}, b_{3}, \ldots, b_{n}\right)
$$

$\circ$ is fuzzy composition operator, $B=\left(b_{1}, b_{2}, b_{3}, \ldots, b_{n}\right)$ is Fuzzy evaluation result vector.

After the fuzzy evaluation result vector is determined, the biggest membership degree principle is adopted to deal with the evaluation index. A fuzzy comprehensive evaluation vector $B=\left(b_{1}, b_{2}, b_{3}, \ldots, b_{n}\right) \quad, \quad$ and if $b_{r}=\max \left\{b_{i}\right\}$, the evaluation factors generally belongs to the $r$ rating, which is the principle of maximum membership degree.

\section{The operation management evaluation index system of the thermal storage electric heating system}

According to the characteristics of the thermal storage electric heating system, combined with users' demand response to the impact of the system efficiency and benefit, the evaluation index system of the thermal storage electric heating system is constructed. The index system includes system operation dimensions, economic dimensions, equipment performance dimension, and user dimension.

In the aspect of management, system operational planning, operation, actual operating cost statistics and deviation correction and so on specific works, need to be equipped with professional personnel, to establish a standard operation management process, to carry out the operation supervision, and implementation of evaluation examination regularly. The operational management, process, supervision, and examination are the main 
influencing factors for equipment efficiency and benefit, which directly determine the system operating level.

In the aspect of cost, the project investment payback period, electricity price fluctuation and subsidy policy are the main influencing factors for equipment efficiency and benefit. The length of the payback period of investment directly affect the level of system efficiency and effectiveness, the shorter the investment payback period, the better project economics. The price fluctuation has significant influence on the system's operating costs. A series of electricity price adjustment scheme introduced gradually recently, which are the regenerative important factor of electric heating system. Government subsidy policies can make up for the expensive construction costs and operating expenses. The subsidies of electric heating system mainly include equipment subsidies, tax breaks, electricity price subsidies, incentives for energy conservation and emissions reduction, etc.

In the aspect of technology, the power rating of electric heating equipment, heat storage capacity, concentration of equipment which are the key technologies for participating in peak regulation of power system to absorb wind power, are the main influencing factors for equipment efficiency and benefit.

In the aspect of user, family structure, income level, housing area, electricity usage factor will affect demand response participation of the thermal storage electric heating system, indirectly affect the electric heating system operation efficiency and benefit.

\section{Fuzzy comprehensive evaluation of the thermal storage electric heating system}

\subsection{Determining the weight of each index using the Analytical hierarchy process method}

Analytical hierarchy process is used to calculate heat storage type electric heating management evaluation index weight. First, a pairwise comparison method is used to construct a judgment matrix for the first-level index of the management evaluation of regenerative electric heating and abandoned wind heating. According to the same method, the judgment matrix of the secondary index layer can be obtained, and finally the management evaluation index system can be quickly obtained.

Table 1. The thermal storage electric heating system operation management evaluation index hierarchical structure model

\begin{tabular}{|l|l|l|l|}
\hline $\begin{array}{l}\text { Standard level } \\
\text { (first index) }\end{array}$ & Weights & $\begin{array}{l}\text { Index level } \\
\text { (secondary index) }\end{array}$ & Weights \\
\hline \multirow{4}{*}{$\begin{array}{l}\text { System operation } \\
\text { dimension }\left(U_{1}\right)\end{array}$} & \multirow{2}{*}{0.1247} & Organization $\left(U_{11}\right)$ & 0.0612 \\
\cline { 3 - 4 } & & Process $\left(U_{12}\right)$ & 0.1248 \\
\cline { 3 - 4 } & & Supervise $\left(U_{13}\right)$ & 0.5275 \\
\cline { 3 - 4 } & Assessment $\left(U_{14}\right)$ & 0.2865 \\
\hline Economic & 0.3271 & Payback & 0.1220 \\
\hline
\end{tabular}

\begin{tabular}{|l|l|l|l|}
\hline dimension $\left(U_{2}\right)$ & & period $\left(U_{21}\right)$ & \\
\cline { 3 - 4 } & & $\begin{array}{l}\text { Electricity price } \\
\text { fluctuations }\left(U_{22}\right)\end{array}$ & 0.3196 \\
\cline { 3 - 4 } & & $\begin{array}{l}\text { Subsidy } \\
\text { policy }\left(U_{23}\right)\end{array}$ & 0.5584 \\
\hline \multirow{4}{*}{$\begin{array}{l}\text { Equipment } \\
\text { performance } \\
\text { dimension }\left(U_{3}\right)\end{array}$} & \multirow{2}{*}{0.4779} & $\begin{array}{l}\text { Rated power }\left(U_{31}\right) \\
\text { Heat storage } \\
\text { capacity }\left(U_{32}\right)\end{array}$ & 0.6483 \\
\cline { 3 - 4 } & & $\begin{array}{l}\text { Equipment } \\
\text { concentration }\left(U_{33}\right)\end{array}$ & 0.2297 \\
\hline \multirow{4}{*}{$\begin{array}{l}\text { User } \\
\text { dimension }\left(U_{4}\right)\end{array}$} & \multirow{2}{*}{0.0703} & $\begin{array}{l}\text { Family } \\
\text { structure }\left(U_{41}\right)\end{array}$ & 0.2999 \\
\cline { 3 - 4 } & & Income status $\left(U_{42}\right)$ & 0.5347 \\
\cline { 3 - 4 } & & Housing area $\left(U_{43}\right)$ & 0.1165 \\
\cline { 3 - 4 } & $\begin{array}{l}\text { Electricity } \\
\text { habit }\left(U_{44}\right)\end{array}$ & 0.0489 \\
\hline
\end{tabular}

4.2 Establishing the evaluation matrix of the secondary evaluation index using the fuzzy comprehensive evaluation method

The establishment of the evaluation matrix is an important link that determines the accuracy of the secondary fuzzy comprehensive evaluation results. According to the characteristics of the thermal storage electric heating system, the industry expert scoring method is used to score the evaluation indicators. The evaluation set mainly considers the degree of influence of each evaluation index on the use efficiency and system benefits of the thermal storage electric heating equipment. A 5-dimensional evaluation set is adopted. Corresponding to the "very large", "large", "normal", "small", and "very small" impact of each evaluation index on the system. The fuzzy comprehensive evaluation consults fifteen relevant experts in related fields. The scoring of experts the expert scoring situation is sorted and normalized, and the system operation dimension management evaluation matrix, the economic dimension management evaluation matrix, the equipment attribute dimension management evaluation matrix, and the user dimension management evaluation matrix are obtained respectively.

$R_{1}=\left[\begin{array}{ccccc}0 & 0.0588 & 0.4118 & 0.2941 & 0.2353 \\ 0 & 0.1176 & 0.4706 & 0.0588 & 0.3529 \\ 0.1176 & 0.4118 & 0.4706 & 0 & 0 \\ 0 & 0.2941 & 0.5882 & 0.0588 & 0.0588\end{array}\right]$

$R_{2}=\left[\begin{array}{ccccc}0 & 0.3529 & 0.4118 & 0.1176 & 0.1176 \\ 0.0588 & 0.5294 & 0.2353 & 0.1765 & 0 \\ 0.0588 & 0.6471 & 0.2353 & 0.0588 & 0\end{array}\right]$

$$
R_{3}=\left[\begin{array}{ccccc}
0.0588 & 0 & 0.2353 & 0.5882 & 0.1176 \\
0 & 0.0588 & 0.2353 & 0.5294 & 0.1765 \\
0 & 0 & 0.2941 & 0.5882 & 0.1176
\end{array}\right]
$$




$$
R_{4}=\left[\begin{array}{ccccc}
0.2941 & 0.4118 & 0.1765 & 0.1176 & 0 \\
0.7647 & 0.1765 & 0.0588 & 0 & 0 \\
0.1765 & 0.1176 & 0.6471 & 0.0588 & 0 \\
0.0588 & 0.1176 & 0.3529 & 0.4706 & 0
\end{array}\right]
$$

\subsection{Fuzzy comprehensive evaluation}

In the evaluation of the operation and management of the thermal storage electric heating system, it is necessary to comprehensively consider the influence of different indicators on the efficiency and benefit of the system equipment. In this paper, the full-factor weighted average fuzzy synthesis operator is used for fuzzy synthesis operation.

$$
b_{j}=\sum_{i=1}^{n} w_{i} r_{i j}
$$

Each evaluation index has a certain contribution to the evaluation goal according to its weight. The calculation process is as follows.

$$
\begin{aligned}
B_{1} & =\left[\begin{array}{llll}
0.0612 & 0.1248 & 0.5275 & 0.2865
\end{array}\right] \cdot\left[\begin{array}{cccccc}
0 & 0.0588 & 0.4118 & 0.2941 & 0.2353 \\
0 & 0.1176 & 0.4706 & 0.0588 & 0.3529 \\
0.1176 & 0.4118 & 0.4706 & 0 & 0 \\
0 & 0.2941 & 0.5882 & 0.0588 & 0.0588
\end{array}\right] \\
& =\left[\begin{array}{lllll}
0.0621 & 0.3198 & 0.5007 & 0.0422 & 0.0753
\end{array}\right]
\end{aligned}
$$

$$
\begin{aligned}
B_{2} & =\left[\begin{array}{lll}
0.1220 & 0.3196 & 0.5584
\end{array}\right] \cdot\left[\begin{array}{ccccc}
0 & 0.3529 & 0.4118 & 0.1176 & 0.1176 \\
0.0588 & 0.5294 & 0.2353 & 0.1765 & 0 \\
0.0588 & 0.6471 & 0.2353 & 0.0588 & 0
\end{array}\right] \\
& =\left[\begin{array}{lllll}
0.0516 & 0.5736 & 0.2568 & 0.1036 & 0.0144
\end{array}\right]
\end{aligned}
$$

$$
\begin{aligned}
B_{3} & =\left[\begin{array}{lll}
0.6483 & 0.2297 & 0.1220
\end{array}\right] \cdot\left[\begin{array}{ccccc}
0.0588 & 0 & 0.5294 & 0.2941 & 0.1176 \\
0 & 0.0588 & 0.4706 & 0.4118 & 0.0588 \\
0 & 0 & 0.2941 & 0.5882 & 0.1176
\end{array}\right] \\
& =\left[\begin{array}{lllll}
0.0381 & 0.0135 & 0.2425 & 0.5747 & 0.1312
\end{array}\right]
\end{aligned}
$$

$$
\begin{aligned}
B_{4} & =\left[\begin{array}{llll}
0.2999 & 0.5347 & 0.1165 & 0.0489
\end{array}\right] \cdot\left[\begin{array}{cccccc}
0.2941 & 0.4118 & 0.1765 & 0.1176 & 0 \\
0.7647 & 0.1765 & 0.0588 & 0 & 0 \\
0.1765 & 0.1176 & 0.6471 & 0.0588 & 0 \\
0.0588 & 0.1176 & 0.3529 & 0.4706 & 0
\end{array}\right] \\
& =\left[\begin{array}{lllll}
0.5205 & 0.2373 & 0.1770 & 0.0651 & 0
\end{array}\right]
\end{aligned}
$$

The fuzzy comprehensive evaluation results of the secondary indicators of the system operation dimension: the membership degree of "very large" impact is $6.21 \%$, the membership degree of "large" impact is $31.98 \%$, the membership degree of "normal" impact is $50.07 \%$, and the membership degree of "small" impact is $4.22 \%$, and the membership degree of "very small" impact is $7.53 \%$. According to the principle of maximum degree of membership, it is obtained that the system operation dimension has a "normal" impact on the efficiency and benefit of the thermal storage electric heating system.

The results of fuzzy comprehensive evaluation of the secondary indicators of economic dimension: the membership degree of "very large" impact is $5.16 \%$, the membership degree of "large" impact is $57.36 \%$, the membership degree of "normal" impact is $25.68 \%$, and the membership degree of "small" impact is $10.36 \%$, and the degree of "very small" impact is $1.44 \%$. According to the principle of maximum degree of membership, it is obtained that the economic dimension has a "large" influence on the efficiency and benefit of the thermal storage electric heating system.

The fuzzy comprehensive evaluation results of the secondary indicators of the equipment performance dimension: the membership degree of "very large" impact is $3.81 \%$, the membership degree of "large" impact is $24.25 \%$, the membership degree of "normal" impact is $57.47 \%$, and the membership degree of "small" impact is $10.36 \%$, and the degree of "very small" impact is $13.12 \%$. According to the principle of maximum degree of membership, it is obtained that the equipment attribute dimension has a "small" impact on the efficiency and benefit of the equipment of the thermal storage electric heating system.

The fuzzy comprehensive evaluation results of the secondary indicators of the user dimension: the membership degree of "very large" impact is $52.05 \%$, the membership degree of "large" impact is $23.73 \%$, the membership degree of "normal"impact is $17.70 \%$, and the membership degree of "small" impact is $6.51 \%$, and the membership degree of "very small" impact is 0 . According to the principle of maximum degree of membership, it is obtained that the user dimension has a "very large" on the efficiency and benefits of the thermal storage electric heating and absorbing equipment.

\section{Conclusion}

In this paper, the analytic hierarchy process is used to construct an evaluation index system and its weights from the system operation dimension, economic dimension, equipment performance dimension, and user dimension to consider the efficiency and benefit of the thermal storage electric heating system. On this basis, the fuzzy comprehensive evaluation method is used to evaluate and analyse the degree of influence of each influencing factor on the efficiency and benefit of the equipment. The results show that in the operation of regenerative electric heating, economy and user participation are the key influencing factors that affect the efficiency and benefit of regenerative electric heating equipment, and provide a powerful reference for improving the operation and management level of regenerative electric heating.

\section{Acknowledgments}

This paper is one of the phase results of the Science and Technology Project of State Grid Corporation, "Application of Optimal Configuration and Interactive Key Technology of Thermal Storage Electric Heating" (5400-201914172A-0-0-00). 


\section{References}

1. United Nations Environment Programme. (2020) Emissions Gap Report 2020.

https://www.unep.org/emissions-gap-report-2020.

2. Verda V, Colella F. (2011) Primary energy savings through thermal storage in district heating networks. Energy, 36(7):4278-4286.

3. Christidis A, Koch C, Pottel L, et al. (2012) The contribution of heat storage to the profitable operation of combined heat and power plants in liberalized electricity markets. Energy, 41(1):75-82.

4. Zhang Tiefeng, Yuan Jinsha,and Kong Huiying. (2006) An Approach Based on AHP/ELECTRE III for Decision-aid in Power Distribution System Planning[J]. Proceeding of the CSEE, 11:121-127.

5. Qin Guangyu, et al. (2021) Comprehensive evaluation of regional energy internet using a fuzzy analytic hierarchy process based on cloud model: A case in China. Energy. 